\title{
Automation of production of concrete mix
}

\author{
Egor Popello ${ }^{1, *}$, and Victoria Gurieva ${ }^{1}$ \\ ${ }^{1}$ Orenburg State University, Orenburg, Russia
}

\begin{abstract}
Computer-aided design of concrete leads to a reduction in terms of production, the exclusion of product deficiencies, improve the quality of manufactured products. This approach allows to produce the concrete to exact physical and mechanical characteristics, which makes the design more reliable and economical. The software package will allow: to reduce the settlement time in the design of concrete mixture, to improve the efficiency of the staff of the laboratory building, to improve the quality of the concrete mix due to higher accuracy of calculations, to apply a flexible approach to the design of concrete mixture in question of introducing new chemical additives and their characteristics.
\end{abstract}

\section{Introduction}

Modern construction is unthinkable without concrete mixtures. They are used in the construction of many manmade structures beginning from building foundations finishing with bridges of high complexity. The minimum possible time and quality of execution are the main criteria that apply to the production of concrete [1-8]. Time for execution order for concrete production depends on many factors such as the level of the process, qualification of personnel and automation of equipment. Apart from the characteristics of the raw materials, the quality of the product depends on all the above factors. Today the need for a concrete with different physical and mechanical properties increase. At the same time, it imposed more stringent requirements on the quality of concrete. In one factory the task of increasing the volume of the concrete issue is solved in the following ways: increasing in production areas, parallelization and extension of technology; performance improvement of existing processes and service of their equipment. But the task of raising the quality of the concrete is the main criterion for the entire production [9-12]. In one factory performance improvement concrete mixing due to the automation of measuring the parameters of the initial components, the automation of the calculation of recipes, raw material supply and preparation of the mixture, dispensing the finished product and its quality indicators.

The technological process of preparation of the concrete mixture with the calculation of the composition and laboratory tests are about 30 days [13-15]. In the works of Doctor of Science prof. Malinina LA, prof. Mikhailov VV, Mironov SA, Frenkel IM, Bazhenov YM and Gorchakov GI noted that the selection of the composition of the concrete mix is one of the most important operations of technological process of production reinforced concrete structures. As a result, the relationship between design components concrete mixture is determined that ensures the strength of concrete in the structure, the mobility of the concrete mix and the concrete efficiency, estimated from the minimum flow rate of the cement. In the adjustment process carried out preliminary tests in order to obtain accurate depending on the properties of concrete, concrete mix of water-cement ratio and other factors. Carrying out these tests, the processing of the results carried out by mathematical methods factorial experiment planning [16]. Thus, it is necessary to automate the design of concrete.

There is a number of difficulties in the process of automation of the design composition of concrete mix. The main difficulty is that the characteristics of the components of the concrete mix and the concrete, which correspond to a satisfactory quality, are in certain ranges of values. The result is that during the installation relationships between parameters concrete, concrete quality prediction have a problem, a promising solution that consists in the use of artificial intelligence in the process.

The object of research is the technological process of manufacturing of concrete for heavy concrete.

The subject of research is the process of computeraided design composition of concrete mixtures.

The aim of this work is reduction the complexity, time designing of concrete mixture and decreasing of defect in the design process for a given quality of concrete.

Based on the goal, the following tasks are:

- To analyze the planning of automation system for the design of the experiment the composition of the concrete mix (CM) and to analyze the system of selection of the composition of concrete mixtures based on use of the composition of chemical additives.

- To develop a simulation model of an automated system (AS) CM on the basis of neural networks (NN).

In the process of solving the problems were used the theory of neural networks, statistical methods, experimental design and factorial analysis. Experimental studies were carried out on the basis of production of LLC "Strojgarant" (Orenburg). Mathematical models of implementation and optimization procedures performed on a computer using a software application. Development

\footnotetext{
* Corresponding author: peplos@inbox.ru
} 
of the AS concrete mixture and planning trials using neural networks was to develop an algorithm and program of the automated designing composition of concrete mixtures.

The general scheme of the process of designing the composition of the concrete mixture is shown in Fig. 1.

The diagram shows the input (left) and output (right) variables. On function entry: P1 - characteristics of the aggregates, P2 - desired characteristics of the concrete mix and of concrete, P3 - characteristic chemical additives. At the exit - mass performance component of ready-mixed concrete, where $\mathrm{C}$ is cement, $\mathrm{S}$ is sand, $\mathrm{CrS}$ is crushed stone, $\mathrm{W}$ is water, $\mathrm{ChA}$ is chemical additives.

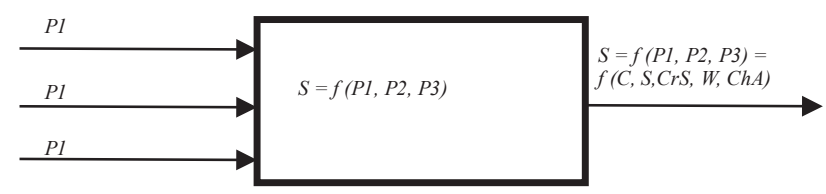

Fig. 1. Scheme of design process of concrete mixture.

Based on neural network, our schemes and techniques as described above, the calculation algorithm settlement and experimental method for composition of heavy concrete aggregates has been developed (Fig. 2).

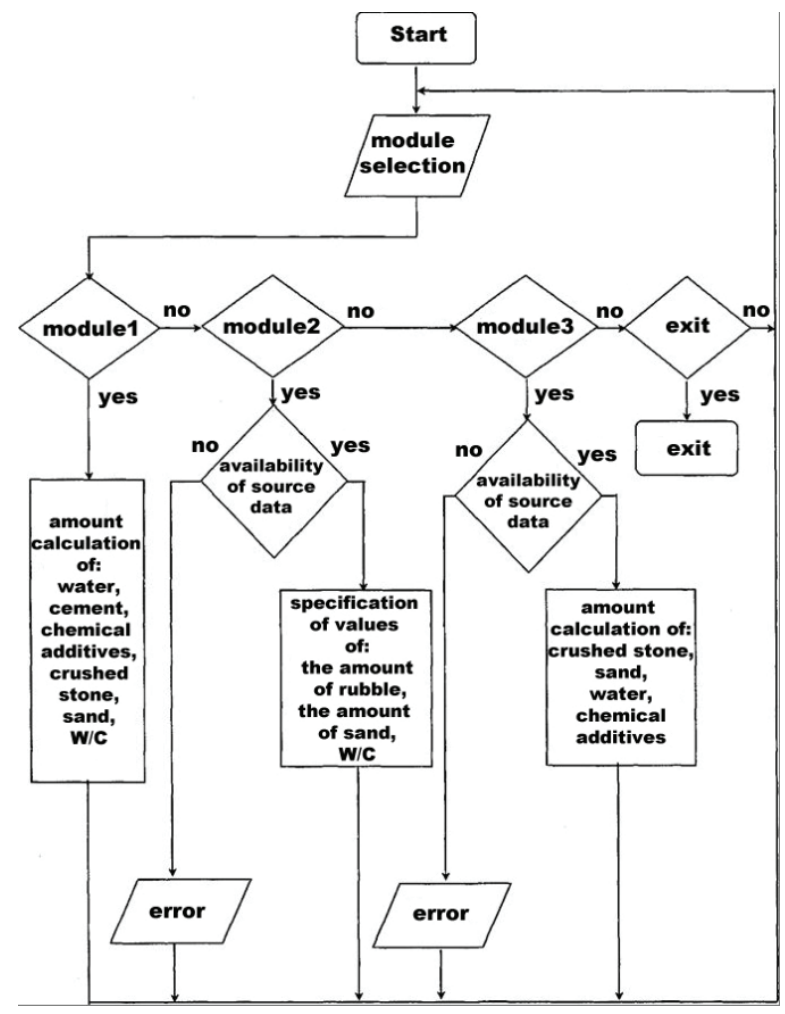

Fig. 2. The structure of the quantitative composition calculation algorithm, the CM.

Three modules stand out in the algorithm. The first module is a theoretical design, the second module is a composition correction, the third module is the preparation of the composition to the transfer of production. Since it is necessary to provide an adjustment of the results and the flexibility of the system, it is used modularity algorithm. The algorithm is shown in Fig. 2. At the entrance of module 1: data aggregates (P1), requirements for the design result $(\mathrm{P} 2)$ and the data on additives (P3) Approximate value of the required watercement ratio $(\mathrm{W} / \mathrm{C})$ is calculated on the basis of the above data. The amount of water for mixing the concrete mixture needed to obtain the desired workability is determined by the maximum size of crushed stone (M_cr, $\mathrm{mm}$ ) and the required mobility $(\mathrm{OK}, \mathrm{cm})$, or stiffness $(\mathrm{ST}, \mathrm{c})$. Consumption of cement is determined by the watercement ratio and the amount of water. Next, the calculation is based on the fact that the sum of the absolute volumes that make up the material is equal to $1 \mathrm{M}^{3}$ tightly laid concrete mix, then the absolute volume of the cement paste and the absolute volume of the mixture of aggregates, the mass of each of the aggregates (sand and gravel) and chemical additives (or additives) of 1 $\mathrm{M}^{3}$ determined. Some of the data which were obtained as a result of the module 1, we apply the algorithm module 2 in the adjustment process $\mathrm{W} / \mathrm{C}$ by changing the amount of water for mixing with the mixture. Adjustment of concrete that's just theoretically designed in Module 1, along with the changes that are obtained in module 2 , we provide the module 3 in order to transfer it into production. This is done by making changes in the quantitative composition of the aggregates with regard to their humidity (W,\%) and conversion to a dry weight of additives which are liquid structure. As a result, the module 3 provides a ready structure of production, which is subjected to laboratory testing for the correct design and modification.

Output function of the final composition of the concrete mix, which is represented in Fig. 1, according to the algorithm and regulatory requirements [13-15], is calculated by the following formula:

$$
S=f\left(P_{1}, P_{2}, P_{3}\right)
$$

each of the input functions $P_{i}$ determined as:

$$
\begin{gathered}
P_{1}=f\left(R_{C}, \mathrm{M}_{C R}^{C S}, p_{S C}, p_{S}, W_{S}, W_{C S}, \frac{S}{C S}\right) \\
P_{2}=f\left(R_{\text {C.requir. }} \frac{W}{C} \mathrm{OK}\right) \\
P_{3}=f\left(\mathrm{~K}_{A}, p_{A}\right)
\end{gathered}
$$

$R_{C}$ - cement Activity $\left(\mathrm{kg} / \mathrm{cm}^{2}\right) ; \mathrm{M}_{C R}^{C S}$ - size gravel unit; $p_{C S}$ и $p_{S}$ - density of crushed stone and sand, respectively; $W_{S}$ и $W_{C S}$ - sand and gravel humidity (\%); $\mathrm{S} / \mathrm{SC}$ - the required ratio between sand and gravel by weight; $\mathrm{W} / \mathrm{C}$ - the desired ratio of water to cement weight; OK - the desired value of the mobility of the concrete mix after it was made $(\mathrm{cm}) ; R_{\text {C.requir. }}-$ the value of the strength of concrete at 28 days after the production of concrete mix $\left(\mathrm{kg} / \mathrm{cm}^{2}\right) ; \mathrm{K}_{A}$ - amount of dry matter additive volume ( $\%$ of the solution $) ; p_{A}$ - additives density.

Function parameters $P_{1}$ и $P_{3}$ are measured by instruments. The required ratio of sand and gravel, water cement relation and mobility (stiffness) of the mixture are taken as parameters to a function $P_{2}$. Further discussed in more detail the method of designing a heavy concrete structure with the help of computational and experimental method. 


$$
\mathrm{W} / \mathrm{C}=f\left(R_{C}, R_{\text {C.requir. }}\right),
$$

The amount of water for mixing $1 \mathrm{~m}^{3}$ of mixture is defined as:

- if the mixture is mobile:

$$
\mathrm{W}=f\left(M, \mathrm{M}_{C R}^{C S}\right),
$$

- if the mixture is stiff:

$$
\mathrm{W}=f\left(R, \mathrm{M}_{C R}^{C S}\right),
$$

whereP is the mobility $(\mathrm{OK})$ of the mixture, $\mathrm{cm}$;

ST is the rigidity of the mixture, $\mathrm{c}$.

Then we calculated the amount of cement for $1 \mathrm{~m}^{3}$ :

$$
\mathrm{C}=f(W / C, W),
$$

Calculate the absolute volume of cement paste (1):

$$
V_{T}=f\left(C, A, W, p_{C S}, p_{S}\right),
$$

The absolute volume of the mixture of aggregates (sand and gravel) (1):

$$
V_{P}=f\left(V_{T}\right)
$$

Then determines the content (mass) of aggregates (sand and gravel):

$$
\mathrm{P}=f\left(V_{P}, p_{P}\right)
$$

Including rubble:

$$
\mathrm{CS}=f(P, r)
$$

where $\mathrm{r}$ - the specified weight ratio of sand and gravel, which is determined by the formula:

$$
\mathrm{r}=f(\mathrm{~S}, \mathrm{CS})=\mathrm{S} / \mathrm{CS}
$$

The amount of sand is determined as the difference between the mass of aggregates $(\mathrm{P})$ and a mass of rubble (CS):

$$
\mathrm{S}=f(\mathrm{P}, \mathrm{CS})
$$

Then recalculate the amount of aggregates takes place in accordance with their humidity, properties and composition of the chemical additives is transferred to the production [17-18].

Currently, a significant number of automated systems offered on the market of software products, they are designed to automate a variety of activities, processes, companies, organizations. A review of existing analogues has been taken to review the program developed by the All-Russian Scientific Research Institute of Physico and Radio Engineering Measurements. The program has a number of advantages such as ease of use, reliability and accuracy of the calculations performed, the high speed of computing.

But in the process of program testing the following weaknesses have been identified in the actual production conditions: firstly, the possibility of introducing the complex of chemical additives in the process of designing the composition of the concrete mix is not considered, secondly, there is no possibility of the water-cement ratio mixture correction; third, it does not counted the humidity of concrete components (sand, gravel), fourth, denied access to the software code. The lack of capability data, the program can not be used effectively in production. the cause of the development of its own software was the inability to integrate functions into the overall project due to the closure of the code. Therefore, the creation of the application is a necessary condition for improving the efficiency of production. A result of analyzing analog disadvantages the standards and recommendations of the experts, the author has developed a software application (SA) for the design the composition and parameters of "MCM" concrete mixture ("Multiple Concrete mixture»). The purpose of the program is the reduction of time and increase the efficiency of the design process and, as a consequence, increase the quality of concrete in its industrial production in the construction industry enterprises.

The system should operate on IBM compatible personal computers. You need a processor with a clock speed of $1 \mathrm{GHz}$ or higher RAM $512 \mathrm{MB}$ of free space on at least $20 \mathrm{MB}$ of hard disk, keyboard, mouse. Just requires the following software: the operating system is not lower than Microsoft Windows 7, Microsoft .NET Framework 4.0, SQLServer [19-24].

Each of the three modules of SA calls user interface which represents the end user dialog. This entry is required for further calculations. The appearance of the user interface is shown in Fig. 3.

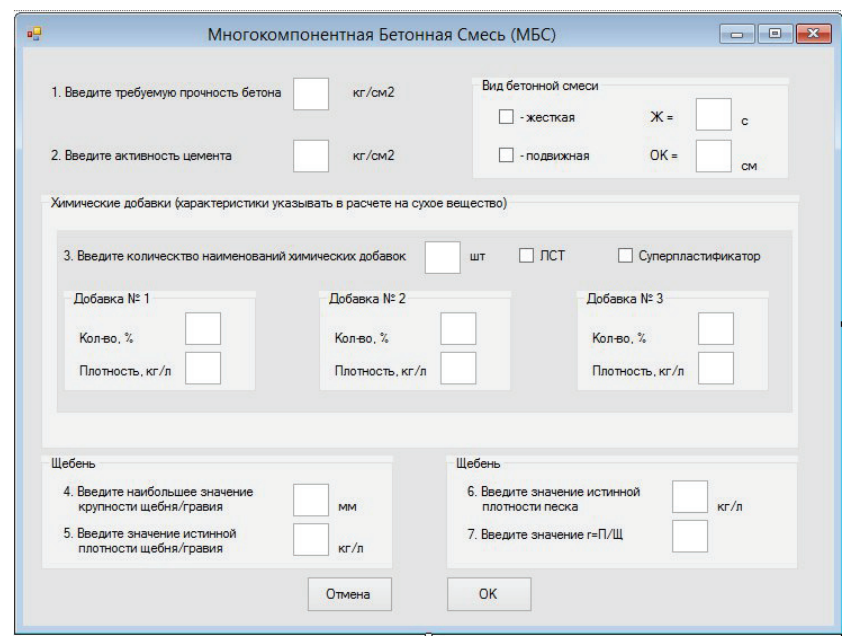

Fig. 3. The main program window.

\section{Insights}

Thus, the efficiency of the developed program is as follows:

- time reduction calculations for designing concrete mixture;

- increase employee productivity construction laboratories;

- improving the quality of the concrete mix due to higher accuracy of calculations;

- a more flexible approach to the process of designing the composition of the concrete mix in the issue of the 
introduction of new chemical additives and their characteristics.

\section{References}

1. V.G. Mikulski, Construction Materials (Textbook.M.: ACB, 2004)

2. K.N. Popov, M. V. Caddo, Construction materials and products (Tutorial. M.: High school, 2002)

3. S.S. Kaprielov, A. V. Sheynfeld, V. G. Batrakov Concrete and reinforced concrete, Complex concrete modifier brand MB-01, 5, 38, (1997)

4. V.I. Kalashnikov, Building materials, Scientific Terminology of the new generation of concretes, $\mathbf{3}$, 103, (2011)

5. S.S. Gordon, Mechanization construction, Production of cold-resistant concrete structures, 7, 22, (2008)

6. J.A. Karasev, Improving the efficiency of cement dispersion systems with water in a metastable state (Author. dissertation of the candidate of technical sciences, 2008)

7. L.I. Dvorkin, O.L. Dvorkin, Fundamentals of Concrete (OOO "Story-Concrete", 200)

8. W. Ken, Concrete mix design, quality control and specification (Academic Press, MA, 2010)

9. V.A. Nevsky, Construction Materials: textbook / under the general editorship (D: Phoenix, 2007)

10. V.S. Izotov, Y. Sokolova, Chemical additives for concrete modifications (monograph M.: Kazan State University of Architecture and Civil Engineering "Paleotypes" Publisher, 2006)

11. I.L. Chulkova, Herald SibADI, Automated calculation of heavy concrete composition and prediction of its properties, 6, 28, (2012)

12. L.I. Kastornov, Additives to concrete and mortar (Phoenix, 2005)

13. SP 130.13330.2011, Manufacture of precast concrete products and (Gosstroy SSSR Moscow: USSR State Committee TSITP, 1988)

14. SNIP 82-02-95, Federal (typical) Element of cement consumption in the manufacture of concrete and concrete products and structures (Gosstroy Russia.M.: FSUE CPP, 1996)

15. GOST 310.1-76 - GOST 310.3-76, GOST 310.4-81, GOST 310.5-80, GOST 310.6-85, Cements. Test methods ( M. Publisher standards, 1985)

16. Y.M. Bazhenov, Methods for determining the composition of different types of concrete, (Tutorial Manual for high schools. M. Stroyizdat, 1975)

17. Guidance on the use of chemical additives in concrete (NIIZhB Gosstroy SSSR. M: Stroyizdat, 1980)

18. Concrete and concrete products (Materials for concrete production. M.: Publishing Standards, 1980)

19. E.C. Mamdani, C. Assilian, An Experiment in Linguistic Synthesys with a Fuzzy Logic Controller, IntI. Man-machine Studies 7, 22, (1975)
20. B. Steinauer, T. Kathmann, G. Mayer, T. Becher, Heft, Einsatzkriterien für Betonschutzwände, Berichte der Bundesanstalt für Straßenwesen, 5, 112 (2004)

21. O. Yagashita, O. Itoh, M. Sugeno, Ed. Amsterdam, Application of fuzzy reasoning to the water purification process, in Industrial Applications of Fuzzy Control,19, (1985)

22. G.G. Kulikov, T.V. Breykin, V.Y. Arkov, Intelligent information systems (Textbook. Benefit / Ufimsk. state. aviation. tehn., 1999)

23. P.A. Gudkov, Systems of artificial intelligence (Method. instructions, 2007)

24. O. Herman, J.O. Herman, Artificial Intelligence (textbook, Belarusian National Technical University, 2013) 